\title{
Comparison between the Early Outcome of Fallot Repair with Preservation of the Pulmonary Valve Annulus versus Transannular Patch Repair
}

\author{
MOHAMED ATTYA, M.D.; AMR BASTAWISY, M.D.; WALEED ISMAIL, M.D. and \\ MICHEAL W. REFAAT, M.B.B.Ch.
}

The Department of Cardiothoracic Surgery, Faculty of Medicine, Ain Shams University

\begin{abstract}
Background: This disease of heart is named after Fallot who correlated the pathologic and clinical manifestations of this cardiac malformation in his description of L'anatomie pathologique de la maladie bleu by 1888 . He was the first to appreciate the complex of this cardiac malformation which he coined a "Tetralogy" consisting of pulmonary stenosis, Ventricular Septal Defect (VSD), dextroposition of the aorta, and RV hypertrophy.
\end{abstract}

Aim of Study: To collect, review and analyze the data of Fallot patient undergoing total repair and to compare the early outcome of Fallot repair with preservation of the annulus versus transannular patch.

Patients and Methods: This is a retrospective analysis which conducted at the Cardiothoracic Surgery at Ain Shams University Hospital from the first of January 2014 till the end of December 2016.

Results: The majority of patients with TOF have a bicuspid or tricuspid PV, which is the most favorable surgical anatomy for preserving the $\mathrm{PV}$, independent of the presence or degree of leaflet dysplasia. We believe that the preservation of the $\mathrm{PV}$ annulus and PV function during early repair of TOF, by combining intraoperative PV dilation and additional surgical procedures, can be extended to the majority of patients with classic TOF. The recent introduction of more-complex PV plasty techniques allowed us to further extend the applicability of PV-preservation techniques.

Conclusion: The optimal repair technique would be therefore, dictated to the anatomical substrate of the lesion, the patient's age, prevailing surgical practice and other patient preoperative characteristics which all should be taken into relevance in an effort to improve patient outcomes.

Key Words: Transannular patch repair-Pulmonary valve annulus - Fallot.

Correspondence to: Dr. Micheal W. Refaat, E-Mail: michealwagih91@gmail.com

\section{Introduction}

IN 1672, Stensen described for the first time the anatomic features of what is now termed Tetralogy of Fallot (TOF) [1] . In 1888, Chastel [2] Arthur Fallot published his findings describing the four features of the congenital cardiac anomaly that bears his name: Infundibular pulmonic stenosis, Ventricular Septal Defect (VSD), and dextroposition of the aorta and Right Ventricular (RV) hypertrophy. Nowadays, TOF repair is a routine practice in many pediatric cardiac centers and can be achieved with a very low surgical risk.

However, the use of a transannular patch, which is still the most common type of repair in the presence of a hypoplastic pulmonary annulus, has proven to be the long-term Achilles' heel in such patients. In fact, it often results in pulmonary insufficiency with chronic RV volume overload, leading to progressive RV dilation and dysfunction, which associated with impaired functional capacity in the long term [3].

Vida and his colleagues [4] have added important insight into ways that surgeons can attempt to affect long-term right heart performance through aggressive attempts to preserve native pulmonary valve function in patients undergoing TOF repair. Through meticulous attention to technical details and native valve morphology, they have been able to "preserve" native pulmonary valve function in $56 \%$ of their patients undergoing TOF repair.

We believe that the preservation of the PV annulus and PV function during early repair of TOF, by combining additional surgical procedures or intraoperative balloon, can be extended to the majority of patients with classic TOF. The recent 
introduction of more-complex PV plasty techniques, including delamination plasty, allowed us to further extend the applicability of PV-preservation techniques [5].

\section{Aim of the work:}

The aim of this work is to collect, review and analyze the data of Fallot patient undergoing total repair and to compare the early outcome of Fallot repair with preservation of the annulus versus transannular patch.

\section{Patients and Methods}

Study design: This is a retrospective analysis.

Study setting: The study was conducted at the Cardiothoracic Surgery at Ain Shams University Hospital.

Study period: This study was from the first of January 2014 till the end of December 2016.

\section{Inclusion criteria:}

Any patient candidate for elective total Fallot repair with pulmonary annulus $\mathrm{Z}$ score -1 to -4 and male or female patient age from 12 months -11 years old.

\section{Exclusion criteria:}

Patients with: Redo Fallot, TOF with AV canal malformations, TOF with absent P.V, TOF with pulmonary atresia, TOF with DORV type, Abnormal course of coronary artery and Post CPR.

\section{Sample size:}

Repair of TOF in the Department of Cardiothoracic Surgery at Ain Shams University Hospital. This is a retrospective study including 80 patients who underwent total repair from the first of January 2014 till the end of December 2016.

\section{Patients were divided into two groups:}

A- Group A: 40 patients who underwent transannular patch.

$B$ - Group B: 40 patients whom pulmonary annulus was preserved.

\section{Study procedure:}

All patients were subjected to the following:

\section{A-Pre-operative:}

1- Detailed history taking; stressing on the age at operation, presence or absence and degree of dyspnea, cyantoic spells frequency, duartion and treatment.
2- General examination; weight, height and body surface area which was calculated based on the Mosteller Formula.

$$
\operatorname{BSA}\left(\mathrm{m}^{2}\right)=\frac{[\text { Height }(\mathrm{cm}) \mathrm{X} \text { Weight }(\mathrm{kg})]}{(3600)^{1} / 2}[6]
$$

3- Cardiac examination; evidence of cardiomegaly, right ventricular dilatation, intensity of $\mathrm{S} 2$ and diastolic murmur of pulmonary regurge.

4- Routine laboratory investigations including haemoglobin, haematocrit, TLC, CRP, coagulation profile, kindney and liver function.

5- Plain CXR to asses cariac size and shape, pulmonary vasculature.

6- ECG: To asses chamber enlargement, rhythm and conduction abnormalities.

7- Echocardiography: 2D Echo and Doppler study was done to demostrate the following: V.S.D. size and anatomy, degree of overriding aorta, the degree and level of the RVOT obstruction, pressure gradient across the RVOT, the size of main pulmonary artery, left and right pulmonary arteries, pulmonary valve annulus size and its $\mathrm{Z}$ score, the left and right ventricle end-diastotlic and end systolic volume and ejection fraction, right ventricular function, Mcgoon ratio and the presence of other abnormalities.

8- MSCT: Was done to confirm the size of pumonary artery and delinate the level of pulmonary artery obstruction, also to demostrate the presence of any abnormal coronary artery, and to asses other vascular structure like MAPCA.

9- Pediatric calculator for accuaracy of the z score of pulmonary annulus and valve. Knowledge of cardiac valve dimensions is important in managing patients with congenital heart diseases. Calculated $\mathrm{Z}$ scores are often used to normalize these measurements to the patient's body weight and height [7]. Regression equations are presented for the mean dimensions and variances across the range of BSA. These equations may be used in the calculation of $\mathrm{z}$ scores that are commonly used in surgical decision making for pediatric patients with TOF [8]

We used the software program with the latest update (Ped Calc version 3.7) to calculate the $Z$ score of the pulmonary valve annulus depending on the weight, height of the patient which formulate the BSA from which the $\mathrm{Z}$ score can be obtained. 


\section{B- Early outcome:}

Follow-up for all our patients post-operatively through 6 months were managed as follow:

\section{Echocardiography to assess:}

Left and right ventricular function, pulmonary and RVOT pressure gradient, residual pulmonary stenosis, grade of pulmonary regurge and other abnormalities or residual VSD.

\section{Ethical consideration:}

1-Delegation of investigator responsibilities: The investigator ensured that all persons assisting the trial are adequately informed about the protocol, and their trial-related duties and functions.

2- Protocol approval:Before the begging of the study and in accordance with the local regulation followed the protocol and all corresponding document was declared for ethical and research approval by the council of the Cardiothoracic Surgery Department, Ain Shams University Hospital.

\section{Statistical analysis:}

The collected data was computed, tabulated, coded, verified and statistically analyzed with the aid of computer program SPSS statistical package version 17.0 on IBM compatible computer. Quantitative data was expressed as mean and standard deviation $(X \pm S D)$, and qualitative data expressed as number and percentage (No. \& \%). Analysis was done by applying Pearson's Chi-Square test and Fisher's exact test. A $p$-value of less than $0.05^{*}$ was considered statistically significant, a $p>0.05$ (non-significant).

\section{Results}

Table (1): Main criteria of all selected patient.

\begin{tabular}{cl}
\hline & Total no. $=80$ \\
\hline Age (years): & $2(1.4-3)$ \\
Median (IQR) & $1-11$ \\
Range & \\
Sex: & $32(40.0 \%)$ \\
Female & $48(60.0 \%)$ \\
Male & \\
Weight $(\mathrm{kg}):$ & $10(8.75-15)$ \\
Median $(\mathrm{IQR})$ & $7-38$ \\
Range & \\
Height $(\mathrm{cm}):$ & $88.31 \pm 17.05$ \\
Mean $\pm \mathrm{SD}$ & $70-134$ \\
Range &
\end{tabular}

The previous table showed that median age was 2 years and ranged from 1 to 11 , there were 32 $(40.0 \%)$ females and $48(60.0 \%)$ males, median weight was $10 \mathrm{~kg}$ and ranged from 7 to 38 , and mean height was $88.31 \pm 17.05$ and ranged from 70 to 134 .

\section{Pre-operative assessment:}

Table (2): Main criteria between the two groups.

\begin{tabular}{|c|c|c|c|c|}
\hline & $\begin{array}{c}\text { Trans-annular } \\
\text { patch } \\
\text { No. }=40\end{array}$ & $\begin{array}{c}\text { Preserved } \\
\text { annulus } \\
\text { No. }=40\end{array}$ & $\begin{array}{c}\text { Test } \\
\text { value }\end{array}$ & $\underset{\text { value }}{p-}$ Sig. \\
\hline $\begin{array}{l}\text { Age (years): } \\
\text { Median (IQR) } \\
\text { Range }\end{array}$ & $\begin{array}{l}2(1.4-2.8) \\
1-9\end{array}$ & $\begin{array}{l}2(1.3-4) \\
1-11\end{array}$ & $-1.328 \neq$ & $0.184 \mathrm{NS}$ \\
\hline $\begin{array}{l}\text { Sex: } \\
\text { Female } \\
\text { Male }\end{array}$ & $\begin{array}{l}17(42.5 \%) \\
23(57.5 \%)\end{array}$ & $\begin{array}{l}15(37.5 \%) \\
25(62.5 \%)\end{array}$ & $0.208^{*}$ & $0.648 \mathrm{NS}$ \\
\hline $\begin{array}{l}\text { Weight }(\mathrm{kg}) \text { : } \\
\text { Median (IQR) } \\
\text { Range }\end{array}$ & $\begin{array}{l}9.5(8.5-12) \\
8-35\end{array}$ & $\begin{array}{l}10.5(9-16.5) \\
7-38\end{array}$ & $-1.164 \neq$ & $0.245 \mathrm{NS}$ \\
\hline $\begin{array}{l}\text { Height }(\mathrm{cm}): \\
\text { Mean } \pm \mathrm{SD} \\
\text { Range }\end{array}$ & $\begin{array}{l}85.63 \pm 15.06 \\
72-126\end{array}$ & $\begin{array}{l}91.00 \pm 18.63 \\
70-134\end{array}$ & $-1.419 \bullet$ & $0.160 \mathrm{NS}$ \\
\hline
\end{tabular}

In group (A) the median age was 2 years (1-9 years), while in group (B) it was 2 years (1-11 years). This difference was statistically insignificant $(p>0.5)$. Table (2).

In group (A) there were 23 males $(57.5 \%)$ and 17 females $(42.5 \%)$, while in group (B) there were 25 males $(62.5 \%)$ and 15 females $(37.5 \%)$. This difference was statistically insignificant.

In group (A) the median weight was 9.5 kilogram $(8-35 \mathrm{~kg})$, while in group (B) it was 10.5 kilogram $(7-38 \mathrm{~kg})$. This difference was statistically insignificant $(p$-value $>0.5$ ).

In group (A) the median height was $85.63 \pm 15.06$ $\mathrm{cm}(72-126 \mathrm{~cm})$, while in group (B) it was $91.00 \pm$ $18.63 \mathrm{~cm}(70-13 \mathrm{~cm})$. This difference was statistically insignificant $(p$-value $>0.5)$.

Table (3): Main echo-cardiographically features of all selected patients (pre-operative).

\begin{tabular}{lll} 
Pre-operative Echo & & Total no.=80 \\
\hline VSD size (mm): & - Mean \pm SD & $12.73 \pm 3.88$ \\
& - Range & $5-22$ \\
VSD anatomy: & - Conoventricular & $16(20.0 \%)$ \\
& - Outlet & $7(8.8 \%)$ \\
& - Perimembranous & $2(2.5 \%)$ \\
& - Subaortic & $55(68.8 \%)$ \\
Degree of overriding & - Mean \pm SD & $47.75 \pm 4.49$ \\
aorta: & - Range & $30-50$ \\
Degree and level of & - Valvular PS & $39(48.8 \%)$ \\
the RVOT obstruction: & - Supravalvular PS & $9(11.3 \%)$ \\
& - Infundibular & $77(96.3 \%)$ \\
& - Hypoplastic PV & $2(2.5 \%)$ \\
Pressure gradient across & - Mean \pm SD & $2(2.5 \%)$ \\
the RVOT (mmh): & - Range & $88.68 \pm 10.11$ \\
\hline
\end{tabular}


The previous table showed that variable size of VSD mean is $12.73 \pm 3.88$ which ranged from 522 , subaortic VSD is the most common VSD site in fallot patients, degree of over riding aorta ranged from $30-50 \%$, the infundibular stenosis the most common level in fallot patients, and the pressure gradient across RVOT ranged from 65-100mmhg.

Table (4): Comparison of the main echo-cardiographic and MSCT features of the two groups (pre-operative).

\begin{tabular}{|c|c|c|c|c|c|}
\hline $\begin{array}{l}\text { Pre-operative } \\
\text { Echo }\end{array}$ & $\begin{array}{c}\text { Trans-annular } \\
\text { patch } \\
\text { (Group A) } \\
\text { No. }=40\end{array}$ & $\begin{array}{c}\text { Preserved } \\
\text { annulus } \\
\text { (Group B) } \\
\text { No.=40 }\end{array}$ & $\begin{array}{c}\text { Test } \\
\text { value }\end{array}$ & $\begin{array}{c}p- \\
\text { value }\end{array}$ & Sig. \\
\hline
\end{tabular}

Degree and level

of the RVOT

obstruction: $\begin{array}{llll}\text { - Range } & 30-50 & 40-50 & 54.484 * 0.000 \mathrm{HS}\end{array}$

- Valvular PS

- Supravalvular PS $7 \quad(17.5 \%)$

- Infundibular $38(95.0 \%)$

- Hypoplastic PV 2 (5.0\%)

- MPA stenosis $2(5.0 \%)$

$3(7.5 \%)$
$2(5.0 \%)$

$39(97.5 \%) \quad 0.346 * \quad 0.556$ NS

$0(0.0 \%) \quad 2.051 * 0.152 \mathrm{NS}$

Pressure gradient

across the RVOT

(mmhg):

- Mean \pm SD

- Range

$90.23 \pm 10.00 \quad 87.13 \pm 10.11 \quad 1.379 \bullet \quad 0.172 \mathrm{NS}$ $65-100 \quad 70-100$

\section{MSCT (MCgoon}

ratio):

$\begin{array}{llll}\text { - Mean } \pm \text { SD } & 1.73 \pm 0.21 & 2.15 \pm 0.29 & -7.453 \bullet 0.000 \mathrm{HS}\end{array}$

\begin{tabular}{lllll}
- Range & $1.4-2.2$ & $1.6-2.7$ & $3.130 *$ & $0.077 \mathrm{NS}$ \\
\hline
\end{tabular}

$p$-value $>0.05$ : Non significant. $*$ : Chi-square test. $p$-value $<0.05$ : Significant.
$p$-value $<0.01$ : Highly significant

The majority of TOF patients show RVOT obstruction at the level of the infundibulum.

Group (A) shows mean valvular stenosis in 36 $(90 \%)$ patients and (group B) in $3(7.5 \%)$ patients and this difference was highly significant.

In group (A) the mean pressure gradient across RVOT measured by echocardiography was 90 mmhg (65-100mmhg), while in group (B) it was $87 \mathrm{mmhg}$ (70-100mmhg). This difference was statistically non significant ( $p$-value $<0.05$ ).

In group (A) the mean Magoon ratio was 1.73 (1.4-2.2) while in group (B) the mean Magoon ratio was $2.15(1.6-2.7)$ this difference was statistically significant ( $p$-value $<0.05$ ).

Post-operative assessment after 6 months:

Table (5): Mortality rate of all selected patients.

\begin{tabular}{lccccc}
\hline $\begin{array}{l}\text { Echo } \\
\begin{array}{l}\text { Post- } \\
\text { operative }\end{array}\end{array}$ & $\begin{array}{c}\text { Trans-annular } \\
\text { patch } \\
\text { No. }=40\end{array}$ & $\begin{array}{c}\text { Preserved } \\
\text { annulus } \\
\text { No. }=40\end{array}$ & $\begin{array}{c}\text { Test } \\
\text { value }\end{array}$ & $\begin{array}{c}p \text { - } \\
\text { value }\end{array}$ & Sig. \\
\hline $\begin{array}{l}\text { Death: } \\
\text { No }\end{array}$ & $\begin{array}{l}38(95.0 \%) \\
\text { Yes }\end{array}$ & $\begin{array}{l}40(100.0 \%) \\
0(5.0 \%)\end{array}$ & $2.051 *$ & .152 & $\mathrm{NS}$ \\
\hline$p$-value $>0.05:$ Non significant. & $\begin{array}{l}p \text {-value }<0.01: \text { Highly significant. } \\
p \text {-value }<0.05: \text { Significant. }\end{array}$ & $*$ : Chi-square test.
\end{tabular}

We have 2 cases mortality in transannular group while we have no mortality in preserved group.

Table (6): Comparison of the main echo-cardiographic features of the two groups (post-operative).

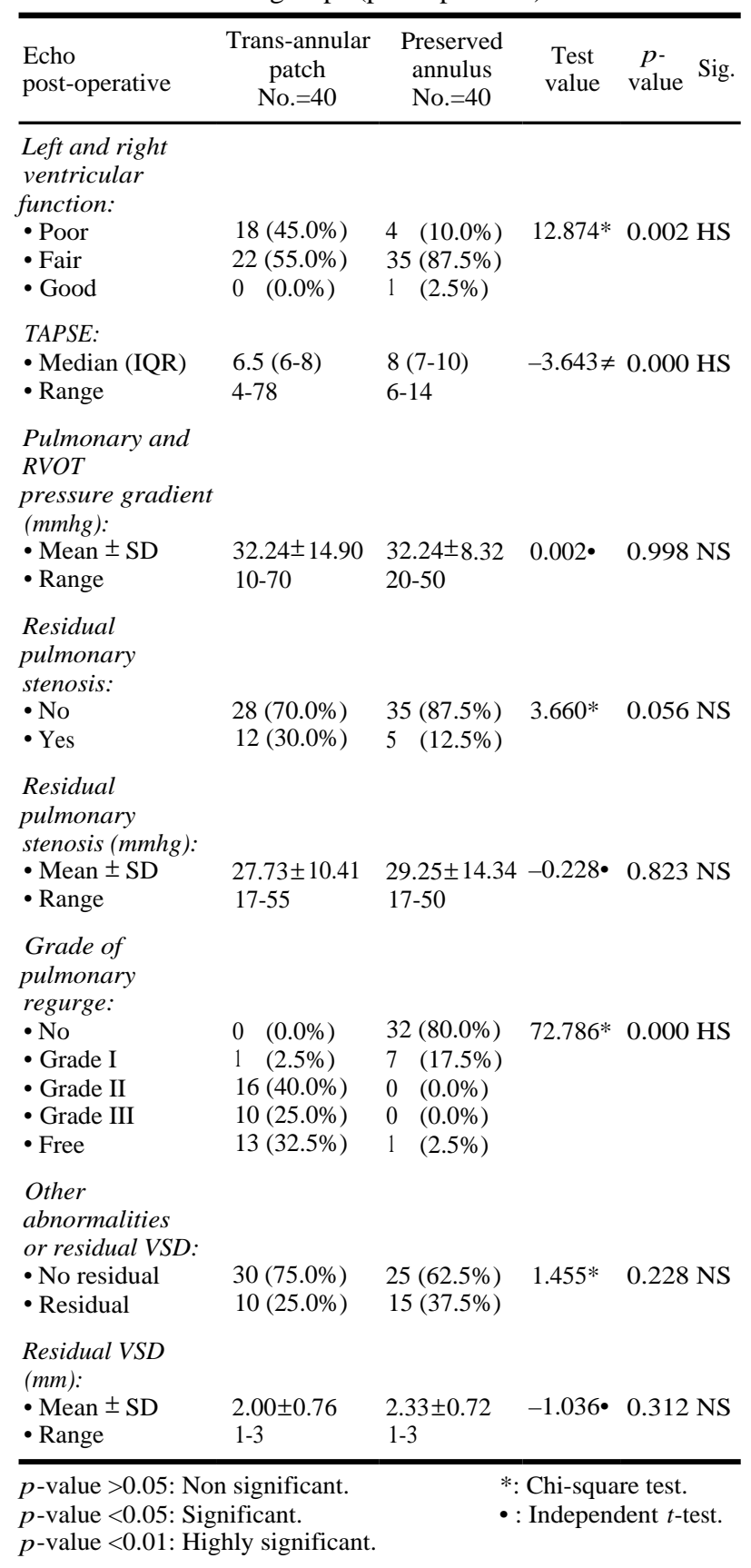

Assessment the 2 groups 6 months follow-up post-operatively by echo according to RV function $\&$ pulmonary stenosis or regurge.

According to $R V$ function: Classified into 3 groups poor, fair \& good according to TAPSE; in (group A) 8 (45\%) patients have poor RV function while (group B) 4 (10\%) patients have poor RV function this difference was statistically significant ( $p$-value <0.05). 
In (group A) $22(55 \%)$ patients have fair RV function while (group B) 35 (87.5\%) patients have fair RV function this difference was statistically significant ( $p$-value $<0.05)$.

In (group A) $0(0 \%)$ patients have good RV function while (group B) 1 (2.5\%) patients have good RV function this difference was statistically significant $(p$-value $<0.05)$.

In (group A) median TAPSE was 6.5 (4-8) patients while (group B) 8 (6-14) patients this difference was statistically significant ( $p$-value $<0.05)$.

According to pulmonary regurge we have 5 grades determine the severity grade 0 , grade 1 , grade 2 , grade $3 \&$ free regurge.

In (group A) $0(0 \%)$ patients have no regurge while (group B) $32(80 \%)$ patients have no regurge this difference was statistically significant ( $p$-value $<0.05)$.

In (group A) $1(2.5 \%)$ patients have grade 1 regurge while (group B) 7 (17.5\%) patients have grade 1 regurge this difference was statistically significant $(p$-value $<0.05)$.

In (group A) 16 (40\%) have grade 2 patients regurge while (group B) $0(0 \%)$ have grade 2 patients regurge this difference was statistically significant ( $p$-value <0.05).

In (group A) 10 (25\%) patients have grade 3 regurge while (group B) 4 (0\%) patients have grade 3 regurge this difference was statistically significant ( $p$-value <0.05).

In (group A) $13(32 \%)$ patients have free regurge while (group B) 1 (2.5\%) patients have free regurge this difference was statistically significant ( $p$-value $<0.05)$.

\section{According to residual pulmonary stenosis:}

Group A 12 (30\%) patients have residual PS and the mean gradient was 27 (17-55mmhg), while group B $5(12.5 \%)$ patients have residual PS and the mean gradient was 29 (17-55mmhg).

This difference was statistically insignificant ( $p$-value >0.05).

\section{Discussion}

Tetralogy of Fallot (TOF) is a well-recognized congenital heart disease involving the combination of Ventricular Septal Defects (VSDs), pulmonary stenosis, and hypertrophy of the Right Ventricle $(\mathrm{RV})$. Previous research has suggested that repairing
TOF in infancy promotes the normal growth and development of the heart and other organs, the elimination of hypoxemia and cyanosis, the prevention of right ventricular hypertrophy, the preservation of left ventricular function, and the decreased incidence of late arrhythmias [9].

An optimal repair of TOF would restore normal Right Ventricular Outflow Tract (RVOT) anatomy and physiology, a pulmonary valve which functions normally without PS. Transannular patching and ventriculotomy started as a therapeutic option for tetralogy of Fallot associated with pulmonary insufficiency and right ventricle dysfunction presenting with exercise intolerance, ventricular dysrhythmias, and a small incidence of sudden death. In 1963, the first transatrial transpulmonary repair by Hudspeth and colleagues was performed. This approach was revisited in the 1990s and is frequently used today in all age groups with a survival rate of greater than $99 \%$ and a low incidence of early intervention [10].

However, the long-standing pulmonary valve incompetence following transannular patch repair of TOF has resulted in excess long-term morbidity and mortality. As a consequence, valve-sparing approaches to TOF repair have gained more attention in recent years. Following the introduction of valve-sparing approaches, the paradigm for surgical repair of TOF has shifted. A prior strategy focused exclusively on relief of PS has changed into one that additionally aims to avoid the now known long-term deleterious consequences of pulmonary regurgitation. Consequently, many surgeons now favor valve-sparing approaches and have extended the boundaries of repair toward pulmonary valve that have previously been considered too small to spare [11].

Nevertheless, there is a scarcity in the published literature regarding the post-operative outcomes following valve-sparing approach versus transannular patches. Therefore, we conducted the present study in order to collect, review, and analyze the data of FOT patient going total repair and to compare the early outcome of Fallot repair with preservation of the annulus versus transannular patch.

The present study was a retrospective study that included 80 patients underwent total repair of TOF in the Department of Cardiothoracic Surgery in Ain-Shams University Hospital from the first of January 2014 till the end of December 2016.

Patients were divided into two groups:

- Group A: 40 patients underwent transannular patch. 
- Group B: 40 patients whom pulmonary annulus was preserved.

A cumulative body of evidence has shown that the best survival and physiological outcomes were achieved with primary repair in children aged 3 to 11 months [12]. However, we found that the mean age at surgery in our cohort was 2 years (range 111 years).

Such delay in repair in our center can be attributed to late diagnosis of neonates or time needed to enter the waiting list for proper preoperative assessment of the patients, furthermore, the patients usually come from far distance from outskirts of our capital which is another obstacle for early intervention.

The ventricular septal defects seen in patients with tetralogy of Fallot are usually perimembranous that can extend into the muscular septum. Different factors can contribute with the RVOT obstruction, including the pulmonary valve that is usually bicuspid and stenotic, the hypoplastic pulmonary valve annulus, the deviation of the infundibular septum that causes a subvalvular obstruction, and the hypertrophy of the muscular bands in this region [13].

Pre-operatively, especially in the neonate, echocardiography can depict site and number of septal defects, degree of septal malalignment and resultant subpulmonary and pulmonary obstruction, anatomy of proximal pulmonary arteries, origin and proximal course of coronaries, presence without full delineation of aortopulmonary collaterals, and $\mathrm{RV}$, tricuspid and pulmonary valve size and qualitative function [14]

In terms of preoperative echocardiographic features of the included patients. Our results showed that the most common type of Ventricular Septal Defect (VSD) was subaortic, followed by conoventricular. On the other hand, the majority of TOF patients show RVOT obstruction at the level of the infundibulum.

In line with our findings, Mostefa-Kara and colleagues [15] aimed to determine the prevalence of VSD in various types of CHD and the distribution of their anatomic types. The authors reviewed 1178 heart specimens with CHD from the anatomic collection of the French Reference Centre for Complex Congenital Heart Defects. In TOF cases (123 cases), the majority of VSD was subaortic.

In addition, Agrawal and colleagues [16] included 51 angiographically proved cases of TOF who were analysed retrospectively for the level(s) of RVOT obstruction. Subvalvular stenosis was found to be the commonest site of RVOT obstruction in $49(96.1 \%)$ patients. Evidence of valvular pulmonary stenosis was seen quite commonly (42/51, $83.9 \%$ cases), mostly in association with obstruction at other sites. Supravalvular stenosis was also seen in $17(33.3 \%)$ cases.

Post-operatively, echocardiography is very useful in evaluation of the RVOT anatomy, size and dynamic or anatomic obstruction, presence of aneurysms and the main and proximal pulmonary artery size, anatomy and residual stenosis, and the degree of PR [14]

In the present study, we used echocardiography to assess the 6-months post-operative outcomes of the included patients. Our results showed that there was statistically significant difference between studied groups in terms of postoperative grade of PR. Patients in preserved annulus group were more likely to have no or grade I PR than patients in transannular patch group. On the other hand, no significant differences were detected in terms of pulmonary and RVOT pressure gradient $(\mathrm{mmHg})$, residual pulmonary stenosis, and residual VSD.

In concordance with our findings, Azzam and colleagues [17] evaluated the results with pulmonary valve preservation versus transannular patch in selected patients with FOT. The study was a prospective, comparative study that enrolled a total of 50 patients, 25 within each group. The degree in PR in pulmonary valve preservation was significantly lower than patients in transannular patch group.

Similarly, Sen and colleagues [11] sought to determine whether a repair that increases the PV annulus and augments the valve leaflet with a biomaterial would result in annular growth and in longer duration of valve competence compared with TAP. Eighty who underwent surgical repair of TOF between 2010 and 2014 were included in the study. Patients were divided into three groups based on the PV intervention: Balloon dilation/ valvotomy $(n=29)$, valve-sparing transannular repair $(n=19)$ and transannular patch $(n=32)$. Compared with transannular patch, valve-sparing transannular repair patients demonstrated significantly less severe PR with $100 \%$ freedom of severe PR immediately post-op., $60 \%$ at 6 months, and $20 \%$ at 20 months.

In addition, Simon and colleagues [18] reported on their results of primary complete repair in 94 TOF infants, using either a limited transannular 
RVOT reconstruction with a Dacron patch tailored to a nominal pulmonary annulus expansion, or an annulus-sparing approach. After a mean followup of approximately 8 years, a more than moderate PR was noticed more frequently in the first group, $50.4 \%$ versus $30.9 \%$, however with reaching a significant difference in freedom from severe PR at 10 years $(73.5 \%$ versus $93.2 \%)$.

Of note, in contrary to our results, the abovementioned three studies reported greater improvements in RVOT pressure gradient $(\mathrm{mmHg})$ and residual pulmonary stenosis. The exact cause of such heterogeneities between our results and the abovementioned studies are unclear. However, this inconsistency can be attributed to the difference in study design, sample size, or employed technique.

Tricuspid Annular Plane Systolic Excursion (TAPSE), measuring the distance of systolic movement of the lateral tricuspid valve annulus in the apical four-chamber view, is generally considered to reflect global RV function [19]

In the present study, we used TAPSE to assess the post-operative ventricular function. The results showed that patients in preserved annulus group were more likely to fair-to-good function than patients in transannular patch group.

To the best of our knowledge, this is the first study that assessed the postoperative ventricular functions through TAPSE. Van den Berg and colleagues [20] assessed the clinical condition at midto-late follow-up in TOF corrected by a transatrialtranspulmonary approach at a young age. Fiftynine patients were included. Compared with patients without a transannular patch, patients with a patch had more pulmonary regurgitation, a larger right ventricle, and worse right ventricular and left ventricular ejection fractions.

Similarly, Yasui and colleagues [21] performed a retrospective study from January 1981 to December 1990 on intracardiac repair of tetralogy of Fallot in 148 pediatric patients was directed toward preservation of the native pulmonary valve. 85 patients were candidates for transannular right ventricular outflow patch. However, in 54 patients, the valve was preserved. The improvement in ventricular function was higher in preservation group.

From the time of first surgical palliation of TOF by Blalock and Taussig in 1945, surgical management has evolved to primary corrective repair that can safely be performed in all age groups. The safety of early primary repair is welldocumented in the literature with several studies showing that it is a safe procedure even in neonate. As a result, primary repair of TOF is now a routine procedure with low surgical mortality rate of 0 $2 \%$ [22].

In the present study, the overall mortality rate was $5 \%$, all of dead infants were in the transannular patch group.

Based on the abovementioned studies and our results, it is more apparent that preservation of the pulmonary valve annulus is more effective than the standard transannular patch. Patients in preserved annulus group are more likely to have no or grade I PR than patients in transannular patch group. Patients in preserved annulus group are more likely to fair-to-good function than patients in transannular patch group as well.

\section{Conclusion:}

The majority of patients with TOF have a bicuspid or tricuspid $\mathrm{PV}$, which is the most favorable surgical anatomy for preserving the PV, independent of the presence or degree of leaflet dysplasia. We believe that the preservation of the PV annulus and PV function during early repair of TOF, by combining intraoperative PV dilation and additional surgical procedures, can be extended to the majority of patients with classic TOF. The recent introduction of more-complex PV plasty techniques allowed us to further extend the applicability of PVpreservation techniques.

The optimal repair technique would be therefore, dictated to the anatomical substrate of the lesion, the patient's age, prevailing surgical practice and other patient pre-operative characteristics which all should be taken into relevance in an effort to improve patient outcomes.

\section{References}

1- WARBURG E.: Niels Stensens Beskrivelse af det forste publicerede Tiflaelde af "Fallots Tetrade." Nord. Med., 16: 3550-1, 1942.

2- CHASTEL É.L.: Mélanges historiques et religieux précédés d'une notice biographique par Aug. Bouvier: (Chastel Étienne Louis). Fischbacher; 1888.

3- KARAMLOU T., SILBER I., LAO R., McCRINDLE B.W., HARRIS L., DOWNAR E., WEBB G.D., COLMAN J.M., VAN ARSDELL G.S. and WILLIAMS W.G.: Outcomes after late reoperation in patients with repaired tetralogy of Fallot: The impact of arrhythmia and arrhythmia surgery. The Annals of Thoracic Surgery, 81 (5): 1786-93, 2006.

4- VIDA V.L., ZUCCHETTA F. and STELLIN G.: Pulmonary valve-sparing techniques during repair of tetralogy of 
Fallot: The delamination plasty. The Journal of Thoracic and Cardiovascular Surgery, 151 (6): 1757-8, 2016.

5- BACHA E.: A functional pulmonary valve after tetralogy of Fallot repair: A fool's errand? The Journal of Thoracic and Cardiovascular Surgery, 155 (3): 1161-2, 2018.

6- EL EDELBI R., LINDEMALM S. and EKSBORG S.: Estimation of body surface area in various childhood ages-validation of the Mosteller formula. Acta Paediatrica., 101 (5): 540-4, 2012.

7- KOESTENBERGER M., NAGEL B., RAVEKES W., AVIAN A., HEINZL B., CVIRN G., FRITSCH P., FANDL A., REHAK T. and GAMILLSCHEG A.: Reference values of tricuspid annular peak systolic velocity in healthy pediatric patients, calculation of z score, and comparison to tricuspid annular plane systolic excursion. The American Journal of Cardiology, 109 (1): 116-21, 2012.

8- PETTERSEN M.D., DU W., SKEENS M.E. and HUMES R.A.: Regression equations for calculation of $\mathrm{z}$ scores of cardiac structures in a large cohort of healthy infants, children, and adolescents: An echocardiographic study. Journal of the American Society of Echocardiography, 21 (8): 922-34, 2008.

9- DIAZ-FRIAS J. and GUILLAUME M.: Tetralogy of Fallot. Stat Pearls, 2019.

10- KHAN S.M., DRURY N.E., STICKLEY J., BARRON D.J., BRAWN W.J., JONES T.J., ANDERSON R.H. and CRUCEAN A.: Tetralogy of Fallot: Morphological variations and implications for surgical repair. European Journal of Cardio-Thoracic Surgery, 56 (1): 101-9, 2019.

11- SEN D.G., NAJJAR M., YIMAZ B., LEVASSEUR S.M., KALESSAN B., QUAEGEBEUR J.M. and BACHA E.A.: Aiming to preserve pulmonary valve function in tetralogy of Fallot repair: Comparing a new approach to traditional management. Pediatric Cardiology, 37 (5): 818-25, 2016.

12- VAN ARSDELL G.S., MAHARAJ G.S., TOM J., RAO V.K., COLES J.G., FREEDOM R.M., WILLIAMS W.G. and McCRINDLE B.W.: What is the optimal age for repair of tetralogy of Fallot? Circulation, 102 (3): Iii-123, 2000.

13- MCLEOD G., SHUM K., GUPTA T., CHAKRAVORTY S., KACHUR S., BIENVENU L., WHITE M. and SHAH S.B.: Echocardiography in Congenital Heart Disease. Progress in Cardiovascular Diseases, 13: 147-53, 2018.

14- APOSTOLOPOULOU S.C., MANGINAS A., KELEKIS N.L. and NOUTSIAS M.: Cardiovascular imaging ap- proach in pre and post-operative tetralogy of Fallot. B.M.C. Cardiovascular. Disorders, 19 (1): 7, 2019.

15- MOSTEFA-KARA M., HOUYEL L. and BONNET D.: Anatomy of the ventricular septal defect in congenital heart defects: A random association? Orphanet Journal of Rare Diseases, 13 (1): 118, 2018.

16- AGRAWAL S., SONI D., DHAWAN S., DWIVEDI S.K., SARAN R.K., PURI V.K., NARAIN V.S. and HASSAN M.: Sites of right ventricular outflow tract obstruction in tetralogy of Fallot--a retrospective study. Indian Heart Journal, 43 (6): 455-9, 1991.

17- AZZAM M.E., MOHAMED A.S., SHAWKY H.A., AHMED T., NOSSIER A.M., MORCOS M.A. and ALI M.G.: Early outcome of fallot repair with preservation of the pulmonary valve annulus versus transannular patch. Journal of Advanced Pharmacy Education \& Research, 8 (1), 2018.

18- SIMON B.V., SWARTZ M.F., EGAN M., CHOLETTE J.M., GENSINI F. and ALFIERIS G.M.: Use of a Dacron annular sparing versus limited Transannular patch with nominal pulmonary annular expansion in infants with tetralogy of Fallot. The Annals of Thoracic Surgery, 103 (1): 186-92, 2017.

19- BONNEMAINS L., STOS B., VAUGRENARD T., MARIE P.Y., ODILLE F. and BOUDJEMLINE Y.: Echocardiographic right ventricle longitudinal contraction indices cannot predict ejection fraction in post-operative Fallot children. European Heart Journal-Cardiovascular Imaging, 13 (3): 235-42, 2011.

20- VAN DEN BERG J., HOP W.C., STRENGERS J.L., De JONGSTE J.C., VAN OSCH-GEVERS L., MEIJBOOM F.J., PATTYNAMA P.M., BOGERS A.J. and HELBING W.A.: Clinical condition at mid-to-late follow-up after transatrial-transpulmonary repair of tetralogy of Fallot. The Journal of Thoracic and Cardiovascular Surgery, 133 (2): 470-7, 2007.

21- YASUI H., NAKAMURA Y., KADO H., YONENAGA K., ASO T., SUNAGAWA H., KANEGAE Y., TOMINAGA R. and TOKUNAGA K.: Preservation of the pulmonary valve during intracardiac repair of tetralogy of Fallot. The Journal of Cardiovascular Surgery, 33 (5): 545-53, 1992.

22- EGBE A.C., MITTNACHT A.J., NGUYEN K. and JOASHI U.: Risk factors for morbidity in infants undergoing tetralogy of fallot repair. Annals of Pediatric Cardiology, 7 (1): 13, 2014. 


\section{المقارنة بين النتائج المبكرة لإصلاح رباعى فالوت إلماتئ

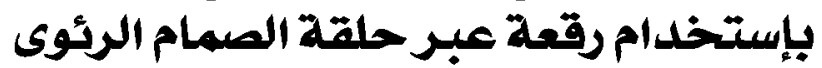

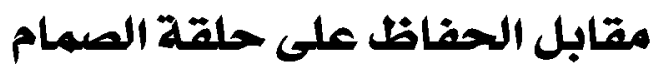

الإصلاح عن طريق رقعة عبر حلقة الصمام الحد نسبة الوفيات بشكل كبير فى رياعى فالوت.

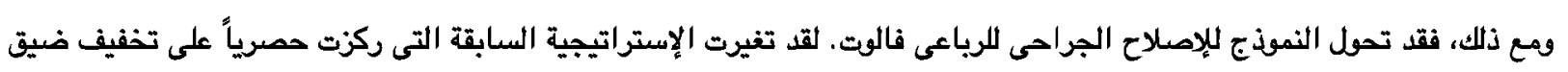

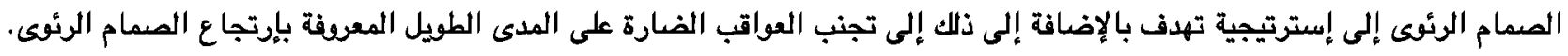

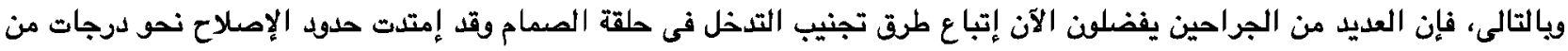

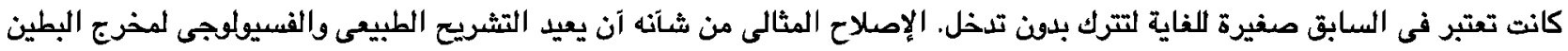

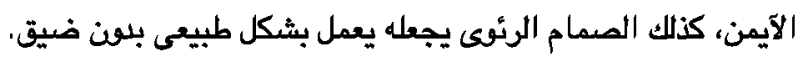

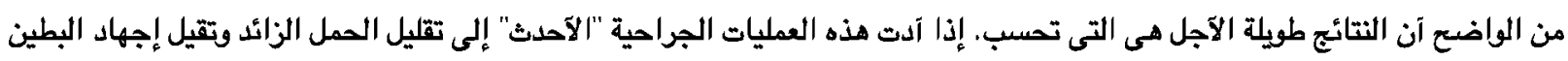
الآيمن، هما يؤلى إلى الحفاظ على وظيفة البطين الآيمن على المدى الطويل، وتقلص الحئ الحاجة إلى العى إعادة عملية جراحية.

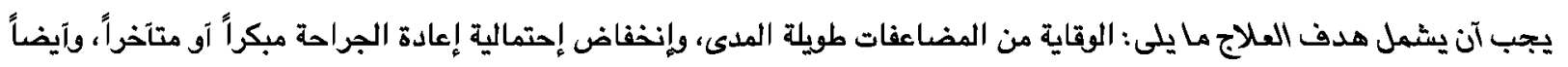

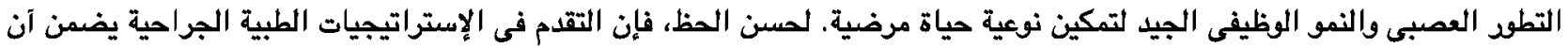

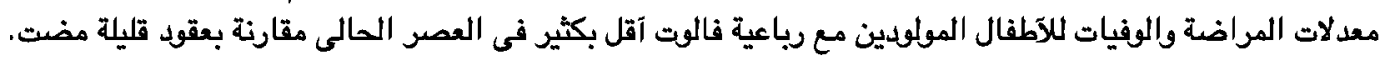

بإختصار، لقد كانت التجرية الآولية مع فلسفة عدوانية لعملية إعادة بناء الصدمات عملية إيجابية، وسنستمر فى تحسين التقنيات الموضحة

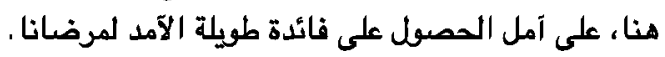

